\title{
Determination of right ventricular wall thickness in systole and diastole Echocardiographic and necropsy correlation in 32 patients
}

\author{
RAVI PRAKASH \\ From the Division of Cardiology, Department of Medicine, University of California Irvine Medical Center, \\ California College of Medicine, Calif., USA
}

SUMMARY To show that right ventricular wall thickness (RVWT) measurements can be made with precision by echocardiography, we correlated these measurements with those obtained at necropsy in 32 terminal patients. The correlation between the echocardiographic diastolic right ventricular wall thickness (mean $4.0 \pm 1.62 \mathrm{~mm}$ ) and the necropsy measurement (inean $4.3 \pm 1.52 \mathrm{~mm}$ ) was good $(\mathrm{r}=0.83)$ in all 32 patients with normal or increased right ventricular wall thickness at necropsy. In 19 patients without necropsy evidence of right ventricular hypertrophy (RVWT $\leqslant 4 \mathrm{~mm}$ ), the mean diastolic and systolic right ventricular wall thicknesses were $3.0 \pm 0.92 \mathrm{~mm}$ and $5.1 \pm 1.64 \mathrm{~mm}$, respectively. In 13 patients with necropsy evidence of right ventricular hypertrophy (RVWT $\geqslant 5 \mathrm{~mm}$ ), the mean diastolic and systolic right ventricular wall thicknesses were $5.3 \pm 1.56 \mathrm{~mm}$ and $8.2 \pm 1.88 \mathrm{~mm}$, respectively. We conclude that technically satisfactory echocardiograms of the right ventricular wall can be obtained in adults and that these allow measurement of systolic and diastolic right ventricular wall thicknesses. Echocardiography can reliably estimate the diastolic wall thickness and may be helpful in the evaluation of right ventricular hypertrophy.

Visualisation of the wall of the right ventricle is difficult in man. The right ventricular free wall is not traceable from cine-angiocardiograms (Arcilla et al., 1976), and can only be measured at necropsy (Sokolow and Lyon, 1949; Allenstein and Mori, 1960; Selzer et al., 1960; Flowers and Horan, 1972). The right ventricular cavity dimension can be estimated by echocardiography by measuring from an assumed location of the anterior border of the right ventricle $5 \mathrm{~mm}$ from the chest wall echoes (Popp et al., 1969; Feigenbaum, 1976) to the right side of the interventricular septum.

Recently, right ventricular wall thickness has been measured in children by echocardiography (Hagan et al., 1973; Solinger et al., 1973; Epstein et al., 1975; Goldberg et al., 1975). These echocardiographic measurements have not been validated with necropsy findings, though the diastolic measurements correlate well with the wall thickness measured using callipers at the time of open heart surgery (Arcilla et al., 1976). Right ventricular wall thickness and motion have not been evaluated in adults and no measurements are available (Joyner,

Received for publication 5 December 1977
1974; Gramiak and Waag, 1975; Chang, 1976; Feigenbaum, 1976). To show that measurements of right ventricular wall thickness can be made with precision in adults by echocardiography we correlated these measurements with those obtained at necropsy in 32 male patients. This paper reports the results of this study.

\section{Subjects and methods}

All terminal patients known to us were studied by echocardiography. Thirty-two of these patients died within one month of echocardiography and necropsy measurements of right ventricular wall thickness were made (Table).

ECHOCARDIOGRAPHIC TECHNIQUE FOR OBTAINING RIGHT VENTRICULAR WALL ECHOES

The echocardiographic recordings were made using a strip chart recorder with the patient in the supine position. A $2 \cdot 25 \mathrm{MHz}$ transducer was used to record the right ventricular wall echoes in all patients. As the chest wall gives strong echoes, this can result in poor resolution of the anterior right ventricular 
Table Correlation of echocardiographic and necropsy measurements of right ventricular wall thickness in all patients

\begin{tabular}{|c|c|c|c|c|c|}
\hline $\begin{array}{l}\text { Patient } \\
\text { number }\end{array}$ & $\begin{array}{l}\text { Age } \\
(y)\end{array}$ & Diagnosis & $\begin{array}{l}\text { Necropsy } \\
(\mathrm{mm})\end{array}$ & $\begin{array}{l}\text { Echocard } \\
\text { ( } \mathrm{mm}) \\
\text { diastole }\end{array}$ & $\begin{array}{l}\text { ogram } \\
\text { systole }\end{array}$ \\
\hline 1 & 56 & Coronary heart disease & 6 & 6 & 10 \\
\hline 2 & 71 & Coronary heart disease & 7 & 6 & 10 \\
\hline 3 & 59 & Cardiomyopathy & 6 & 5 & 7 \\
\hline 4 & 63 & Coronary heart disease & 6 & 5 & 7 \\
\hline 5 & 87 & Cardiomyopathy & 6 & 7 & 9 \\
\hline 6 & 57 & Coronary heart disease & 5 & 6 & 9 \\
\hline 7 & 38 & Coronary heart disease & 5 & 5 & 8 \\
\hline 8 & 39 & Coronary heart disease & 5 & 5 & 8 \\
\hline 9 & 48 & Coronary heart disease & 5 & 5 & 7 \\
\hline 10 & 78 & Coronary heart disease & 3.5 & 4 & 6 \\
\hline 11 & 54 & Coronary heart disease & 3 & 2 & 5 \\
\hline 12 & 76 & Coronary heart disease & 3 & 3 & 4 \\
\hline 13 & 55 & Coronary heart disease & 3 & 3 & 4 \\
\hline 14 & 59 & Coronary heart disease & 2 & 2 & 3 \\
\hline 15 & 61 & Cardiomyopathy & 4 & 3 & 5 \\
\hline 16 & 56 & Cardiomyopathy & 3 & 3 & 4 \\
\hline 17 & 84 & Coronary heart disease & 3 & 4 & 8 \\
\hline 18 & 62 & Cardiomyopathy & 3 & 3 & 5 \\
\hline 19 & 60 & Coronary heart disease & 4 & 2 & 5 \\
\hline 20 & 66 & Coronary heart disease & 4 & 2 & 5 \\
\hline 21 & 56 & Coronary heart disease & 3 & 2 & 6 \\
\hline 22 & 62 & Coronary heart disease & 3 & 3 & 5 \\
\hline 23 & 45 & Coronary heart disease & 3 & 3 & 5 \\
\hline 24 & 56 & Coronary heart disease & 3 & 2 & 2 \\
\hline 25 & 50 & Cardiomyopathy & 4 & 2 & 5 \\
\hline 26 & 64 & Cardiomyopathy & 7 & 6 & 10 \\
\hline 27 & 48 & Coronary heart disease & 6 & 5 & 9 \\
\hline 28 & 60 & Cardiomyopathy & 6 & 6 & 10 \\
\hline 29 & 56 & Coronary heart disease & 6 & 6 & 10 \\
\hline 30 & 81 & Coronary heart disease & 4 & 5 & 9 \\
\hline 31 & 54 & Coronary heart disease & 3 & 3 & 5 \\
\hline 32 & 40 & Cardiomyopathy & 4 & 4 & 6 \\
\hline
\end{tabular}

wall. It was necessary to adjust carefully the coarse gain, near gain, and depth compensation controls to record right ventricular wall echoes adequate for measurement of wall thickness. Placement of the depth compensation ramp and its angle of slope are not fixed for recording the right ventricular wall. This control is used to suppress echoes close to the transducer and to increase the intensity of echoes farther away from the transducer. The depth compensation settings recommended for echocardiographic examination of the left ventricle (Chang, 1976) are not appropriate for obtaining echograms of the right ventricular wall.

In our experience, right ventricular wall echoes were clearly seen only when we specifically looked for them. On a routine echocardiogram for a left ventricular study, the right ventricular wall was not well defined (Fig. 1A, left panel). On reducing the near gain, the right ventricular wall echoes were better seen (Fig. 1A, right panel). In the last two beats the right ventricular wall echoes are reasonably clear, though the right ventricular wall could not be completely separated from the chest wall. In Fig. 1B, separation of right ventricular wall from the chest wall was achieved by decreasing the near $\stackrel{\overrightarrow{\vec{F}}}{\overrightarrow{0}}$ gain and increasing the coarse gain. Though the right ventricular wall is well seen in both panels of Fig. 1B, the left panel is better suited for assessing the right ventricular wall thickness and motion than the right panel, as it has higher gain and darker colour. The right ventricular wall shows a posterior $\delta$ motion away from the chest wall during systole, and $\vec{\circ}$ is thicker in systole than in diastole (Figs 2 and 3). The anterior echo-free space seen in Fig. 1B is not the result of the pericardial effusion. No posterior echo-free space was present in any patient though we specifically looked for pericardial effusion by standard techniques (Horowitz et al., 1974). The right ventricular wall thickness was measured from the pericardium to the endocardial surface of the $O$ right ventricle at a level where the interventricular 의 septum, mitral valve, and posterior left ventricular wall were well seen; end-diastolic measurements $Z$ were made at the beginning of QRS, and systolic measurements when right ventricular wall thickness was greatest.

\section{NECROPSY TECHNIQUES}

At necropsy the hearts were dissected in a uniform manner and the right ventricular wall thickness measurements were made without knowledge of the echocardiographic measurements. The right ventricular wall thickness was measured in millimetres with a ruler, in the mid-portion of the free wall of the right ventricle (between the base and the apex). Sections were carefully made to avoid the valleys between the trabeculations. The normal right ventricular wall thickness at necropsy is $2 \mathrm{~mm}$, and right ventricular hypertrophy is usually considered to be present if the wall thickness is $5 \mathrm{~mm}$ or more.

\section{Results}

The diastolic and systolic measurements of right ventricular wall thickness were correlated with the necropsy measurements. The correlation between diastolic wall thickness measured by echocardio- $\frac{T}{0}$ graphy (mean $4.0 \pm 1.62 \mathrm{~mm}$ ) and at necropsy $(4.3 \pm 1.52 \mathrm{~mm})$ was good $(r=0.83)$ in all $32 \%$ patients (Fig. 4). The correlation between the $N$ systolic wall thickness measured by echocardio- N graphy $(6.4 \pm 2.42 \mathrm{~mm})$ and at necropsy was less $\operatorname{good}(r=0.59)$.

There were 19 patients without right ventricular $\stackrel{0}{=}$ hypertrophy, having a wall thickness $4 \mathrm{~mm}$ or less $\stackrel{\mathbb{\infty}}{\rightarrow}$ at necropsy. The mean diastolic right ventricular wall thickness measured at echocardiography was $3.0 \pm 0.92 \mathrm{~mm}$ (range $2-5 \mathrm{~mm}$ ) and the mean systolic measurement was $5 \cdot 1 \pm 1.64 \mathrm{~mm}$ (range $\frac{\rho}{\Phi}$ 2-9 $\mathrm{mm}$ ). 


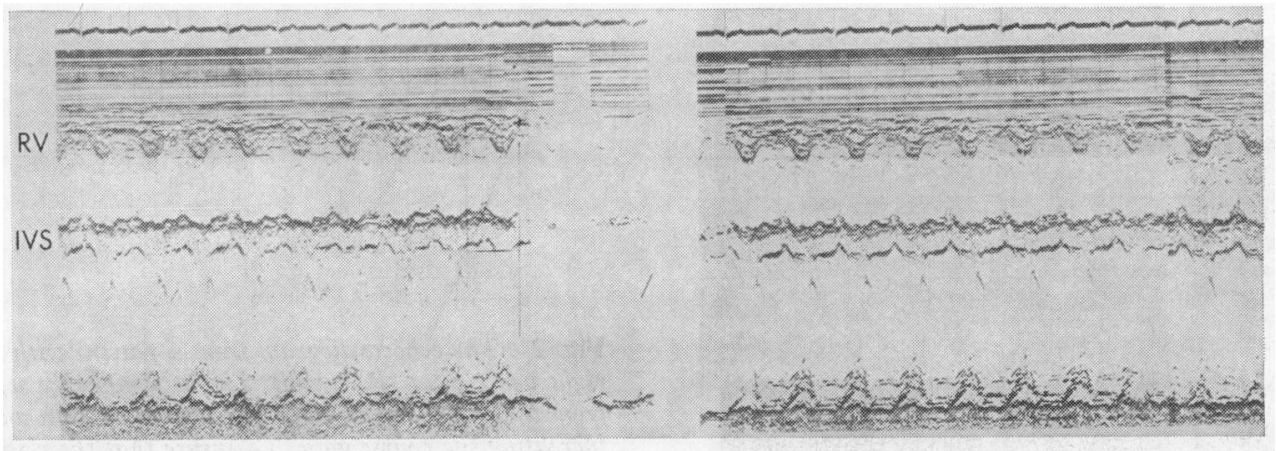

Fig. 1(A)

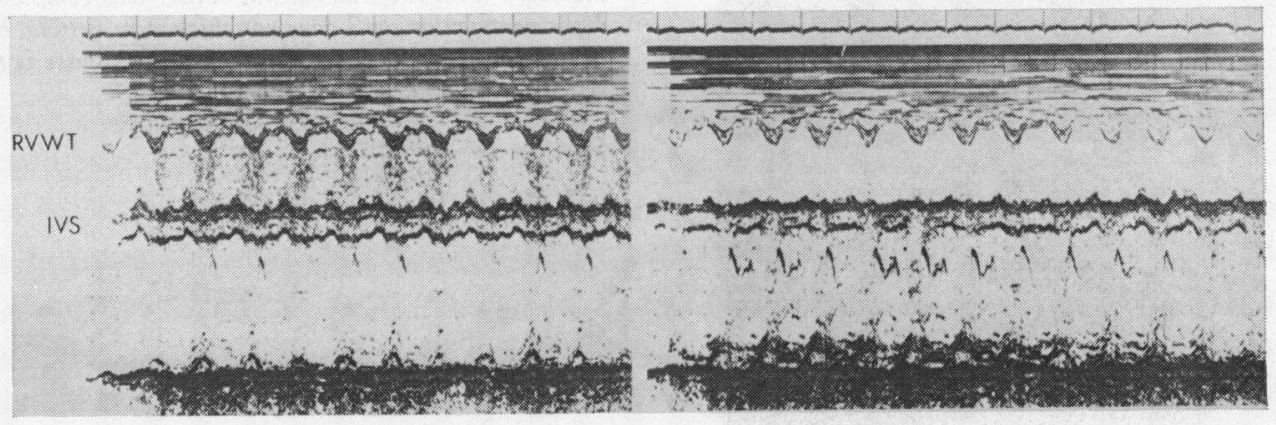

Fig. 1(B)

Fig. 1(A) (left panel) Right ventricular $(R V)$ wall seen on a routine study is not separate from the chest wall echoes. This is because of a high near gain. On the right side of left panel the gain is decreased abruptly with the right ventricular wall almost disappearing. (right panel) The right ventricular wall is seen better. The endocardial margins are more distinct, but the right ventricular wall and chest wall echoes are still close to each other. Though this echo is not optimal for right ventricular wall thickness measurement, the right ventricular dimension can be accurately measured from the endocardium. of the right ventricular wall to the right side of septum. Thus, one would not have to use the customary approximation of about $0.5 \mathrm{~cm}$ from the chest wall echoes as to the location of the anterior border of the right ventricle. The last two beats of the tracing show a clear right ventricular wall. (B) An optimal right ventricular wall recording from the same patient. The chest wall echoes have been suppressed by manipulation of the near gain, coarse gain, and the depth compensation controls. The right ventricular wall is separated from the chest wall by an anterior echo-free space not caused by a pericardial effusion. The thickness and motion of the right ventricular wall can be evaluated from this echocardiogram. During systole the right ventricular wall thickens and moves away from the chest wall in a posterior direction. The right panel shows a reduction in gain with virtual disappearance of the right ventricular wall echoes in the last few beats.

There were 13 patients with right ventricular hypertrophy as evidenced by right ventricular wall thickness $5 \mathrm{~mm}$ or more at necropsy. The mean diastolic wall thickness measurement by echocardiography was $5.3 \pm 1.56 \mathrm{~mm}$ (range $5.6 \mathrm{~mm}$ ) and the mean systolic thickness measurement was $8 \cdot 2 \pm 1.88 \mathrm{~mm}$ (range 6-10 $\mathrm{mm}$ ).

\section{Discussion}

Our data show that echocardiographic measurements of diastolic right ventricular wall thickness correlate well ( $r=0.83$ ) with necropsy measurements. This is supported by the study of Arcilla et al. (1976) where good correlation $(r=0.87)$ was found in 15 children between right ventricular wall thickness measured with callipers at the time of open heart surgery and that obtained by echocardiography. In our study the mean diastolic wall thickness was $3.0 \mathrm{~mm}$ in patients without right ventricular hypertrophy, and was $5.3 \mathrm{~mm}$ in patients with necropsy evidence of right ventricular hypertrophy. Similarly, the mean systolic right ventricular wall thickness was $5.1 \mathrm{~mm}$ in patients without right ventricular 


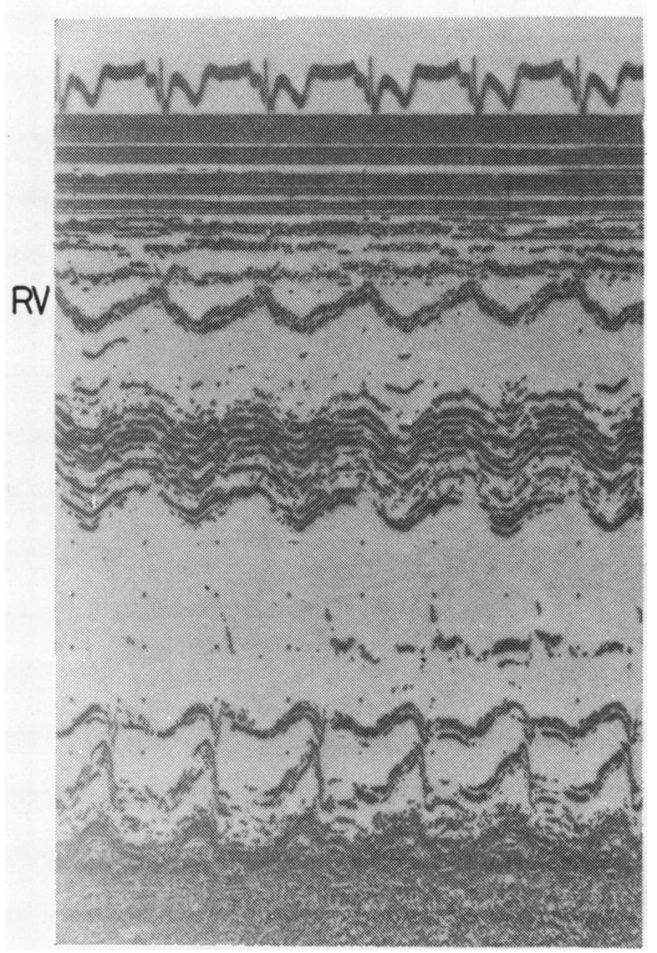

hypertrophy, and was $8.2 \mathrm{~mm}$ in patients with necropsy evidence of right ventricular hypertrophy. These measurements of right ventricular wall thick-
Fig. 2 The echocardiogram from a patient with a thin right ventricular $(R V)$ wall. This is completely separated from the chest wall by decreasing the near gain and increasing the coarse gain. To ensure that the right ventricular wall thickness was seen in full, the gain was increased until the endocardial border was complete. The right ventricular wall does not thicken in systole, but has very good motion. The anterior echo-free space is not the result of a pericardial effusion.

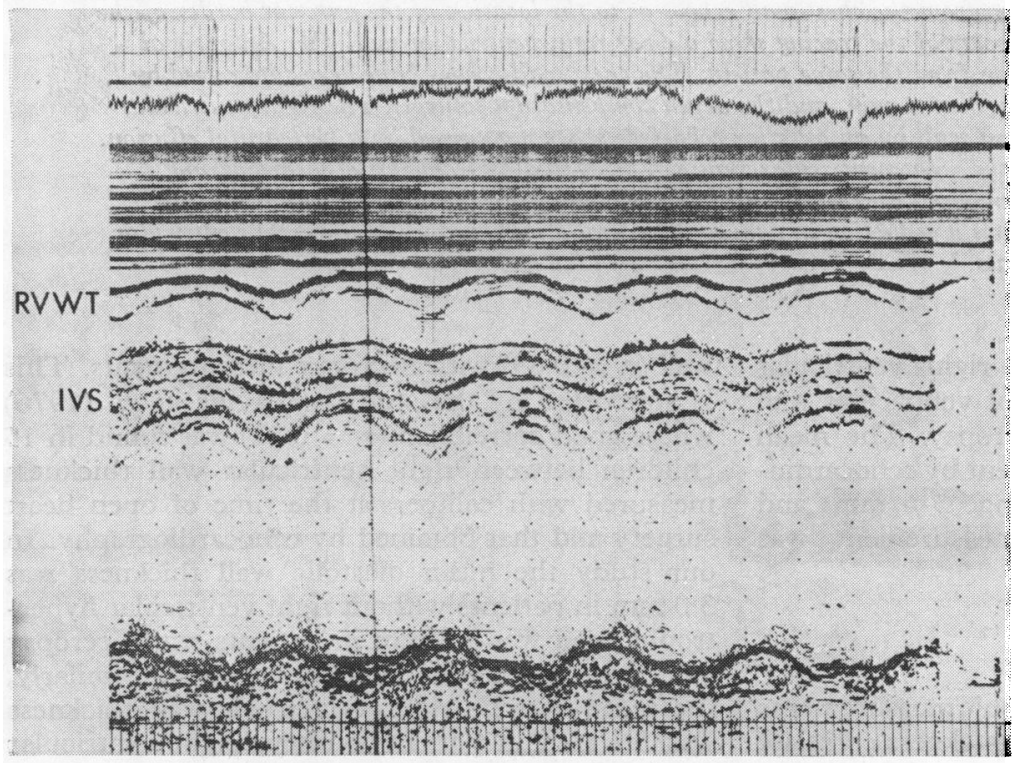

Fig. 3 A distinct right ventricular wall completely separated from the chest wall by an echofree space (not due to pericardial effusion) is shown here. Both margins of the right ventricular wall are distinct, and the diastolic $N$ and systolic measurements of its thickness can be accurately made. The right ventricular wall thickens during systole, has good motion, and displays a posterior motion away from the chest wall. ventricular hypertrophy and right ventricular mass (Arcilla et al., 1976). 


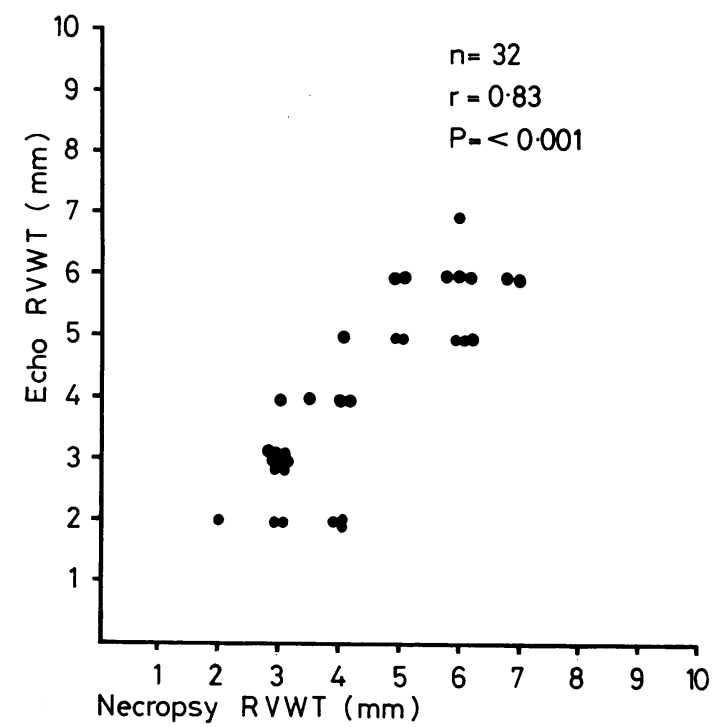

Fig. 4 Correlation between the echocardiographic measurements of right ventricular wall thickness $(R V W T)$ and the necropsy measurements was good $(r=0.83)$ in 32 patients. The diastolic $R V W T$ for all patients ranged between 2 and $6 \mathrm{~mm}$ (mean $4.0 \pm$ $1.62 \mathrm{~mm}$ ), the systolic $R V W T$ ranged between 2 and $10 \mathrm{~mm}$ (mean $6.4 \pm 2.42 \mathrm{~mm}$ ), and the necropsy $R V W T$ ranged between 2 and $7 \mathrm{~mm}$ (mean $4 \cdot 3 \pm$ $1.52 \mathrm{~mm}$ ).

It has been said that the anterior right ventricular wall is difficult to record in the absence of significant anterior pericardial effusion and is clearer in the presence of exaggerated motion, as seen in hypertrophic subaortic stenosis (Feigenbaum, 1976). In our study, the recording of clear right ventricular wall echoes was unrelated to the magnitude of right ventricular wall excursion. Furthermore an anterior echo-free space could be seen in the absence of pericardial effusion, as has been described before (Solinger et al., 1973; Horowitz et al., 1974; Epstein et al., 1975). Our success in obtaining satisfactory right ventricular wall echoes is in large part the result of our interest in measuring wall thickness and not because of new technical advances. Good quality echograms appropriate for right ventricular wall thickness measurement were obtained in nearly 90 per cent of subjects up to 18 years of age by Arcilla et al. (1976), and in 73 of 77 children by Allen et al. (1977).

We conclude that technically satisfactory echocardiograms of the right ventricular wall can be obtained in men which allow measurements of systolic and diastolic wall thickness. Measurements of diastolic right ventricular wall thickness by echocardiography correlate well with necropsy measurements, and may be useful in the noninvasive evaluation of right ventricular hypertrophy and mass in man.

We thank Dr Paul Lindsay and Miss Becky Brotton for help with this study.

\section{References}

Allen, H. D., Goldberg, S. J., Sahn, D. J., Schy, N., and Wojcik, R. (1977). A quantitative echocardiographic study of champion childhood swimmers. Circulation, 55, 142-145.

Allenstein, B. J., and Mori, H. (1960). Evaluation of electrocardiographic diagnosis of ventricular hypertrophy based on autopsy comparison. Circulation, 21, 401-412.

Arcilla, R. A., Mathew, R., Sodt, P., Lester, L., Cahill, N., and Thilenius, O. G. (1976). Right ventricular mass estimation by angioechocardiography. Catheterization and Cardiovascular Diagnosis, 2, 125-136.

Chang, S. (1976). M-Mode Echocardiographic Techniques and Pattern Recognition. Lea and Febiger, Philadelphia.

Epstein, M., Goldberg, S. J., Allen, H. D., Konecke, L., and Wood, J. (1975). Great vessel, cardiac chamber and wall growth patterns in normal children. Circulation, 51, 1124-1129.

Feigenbaum, H. (1976). Echocardiography. Lea and Febiger, Philadelphia.

Flowers, N. C., and Horan, L. G. (1972). In Advances in Electrocardiography, pp. 297-308. Ed. by R. C. Schlant and J. W. Hurst. Grune and Stratton, New York and London.

Goldberg, S. J., Allen, H. D., and Sahn, D. J. (1975). Pediatric and Adolescent Echocardiography. Year Book Medical Publishers, Chicago.

Gramiak, R., and Waag, R. C. (1975). Cardiac Ultrasound. C. V. Mosby, Saint Louis.

Hagan, A. D., Deely, W. J., Sahn, D., and Freidman, W. F. (1973). Echocardiographic criteria for normal newborn infants. Circulation, 48, 1221-1226.

Horowitz, M. S., Schultz, C. S., Stinson, E. B., Harrison, D. C., and Popp, R. L. (1974). Sensitivity and specificity of echocardiographic diagnosis of pericardial effusion. Circulation, 50, 239-247.

Joyner, C. R. (1974). Ultrasound in the Diagnosis of Cardiovascular Pulmonary Disease. Year Book Medical Publishers, Chicago.

Popp, R. L., Wolfe, S. B., Hirata, T., and Feigenbaum, H. (1969). Estimation of right and left ventricular size by ultrasound. American fournal of Cardiology, 24, 523-530.

Selzer, A., York, E., Naruse, D. Y., and Pierce, D. H. (1960). Electrocardiographic findings in 500 cases with hypertrophy of cardiac ventricles. American fournal of the Medical Sciences, 240, 543-550.

Sokolow, M., and Lyon, T. P. (1949). The ventricular complex in right ventricular hypertrophy as obtained by unipolar precardial and limb leads. American Heart fournal, 38, 273-294.

Solinger, R., Elbl, F., and Minhas, K. (1973). Echocardiography in the normal neonate. Circulation, 47, 108-118.

Requests for reprints to Dr Ravi Prakash, Cardiology Division, University of California Irvine Medical School, 101 City Drive South, Orange, California 92668, USA. 